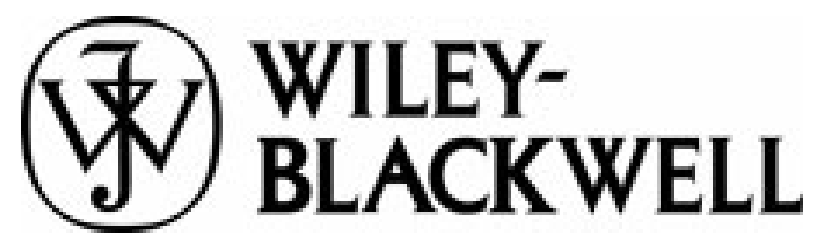

\title{
American Finance Association
}

A Note on the Return Behavior of High Risk Common Stocks

Author(s): Richard W. McEnally

Reviewed work(s):

Source: The Journal of Finance, Vol. 29, No. 1 (Mar., 1974), pp. 199-202

Published by: Blackwell Publishing for the American Finance Association

Stable URL: http://www.jstor.org/stable/2978225

Accessed: 23/05/2012 17:47

Your use of the JSTOR archive indicates your acceptance of the Terms \& Conditions of Use, available at http://www.jstor.org/page/info/about/policies/terms.jsp

JSTOR is a not-for-profit service that helps scholars, researchers, and students discover, use, and build upon a wide range of content in a trusted digital archive. We use information technology and tools to increase productivity and facilitate new forms of scholarship. For more information about JSTOR, please contact support@jstor.org. 


\title{
A NOTE ON THE RETURN BEHAVIOR OF HIGH RISK COMMON STOCKS
}

\author{
RICHARD W. MCENALLY*
}

High RISK COMmon stocks, it is frequently observed, do not appear to generate returns commensurate with the level of associated risk. This conclusion has been reached in investigations which utilize return behavior constructs of risk as well as in those which quantify risk by reference to "agency ratings" of investment quality. For example, in a widely cited but unpublished study, Pratt [9] found that when NYSE common stocks were sorted into five groups according to the rank of the variance of their monthly returns in successive thirty-six monthly periods in the years 1926-1959, on the average the mean group return in the following twelve months rose with increasing variance-except for the group containing the highest variance common stocks. ${ }^{1}$ In a similar vein, Soldofsky and Miller [14] constructed indices of the returns from six investment advisory service common stock quality classes over the 1951-1966 period. They found that the geometric mean annual return from the lowest grade of stocks was less than half the equivalent return from any of the less risky classes.

A number of explanations have been offered for the poor performance of high risk stocks, most of which are somewhat $a d$ hoc in nature. It has been variously suggested that this phenomenon is due to (1) the impact of an excessive number of investors with relatively limited risk aversion who are willing to accept high risk in exchange for high expected returns but, lacking access to the borrowing necessary to lever up the returns from lower risk stocks, seek out high risk stocks and bid down their returns [3, p. 53]; (2) the failure of conventional return measures to give appropriate consideration to the favored tax treatment of the capital gains component of returns which presumably is more important for lower quality stocks [3, p. 52]; and (3) the tendency of investors to be overly optimistic in appraising the potential performance of high risk common stocks $[3$, p. $54 ; 10$, p. $350 ; 11$, p. 238]. The purpose of this note is to suggest that the return behavior of high risk common stocks is at least consistent with the emphasis of Hicks [5, p. 125], Hirschleifer [6, p. 113], Arditti $[1,2]$ and others on the importance of higher moments of the distribution of returns in investor utility functions and hence in the determination of the structure of security yields. ${ }^{2}$

* University of Texas at Austin.

1. A revised version [10] of this investigation has recently been published.

2. Arditti [1] showed through multiple regression analysis that the first moment of the distribution of realized security returns is positively related to the second moment and negatively related to the third moment of the distribution. However, this result is not sufficient to rationalize the return behavior of high risk common stocks in the absence of a demonstrated relationship between the third moment of the distribution and either the second moment or some other measure of risk. Another recent multiple regression analysis of return determinants by Huntsman [7] was specified in such a manner as to give cognizance to interactions among the moments- 
TABLE 1

Selected Measures of the Distributions of Monthly Holding Period Returns of Individual Common Stocks, 1945-1965

(In Five Groups of 109 Stocks Each)

\begin{tabular}{lllccc}
\hline \hline & \multicolumn{5}{c}{ Group } \\
\cline { 2 - 6 } & \multicolumn{1}{c}{1} & \multicolumn{1}{c}{2} & \multicolumn{1}{c}{3} & \multicolumn{1}{c}{4} & \multicolumn{1}{c}{5} \\
\hline $\begin{array}{l}\text { Grand Mean of HPR's } \\
\text { Mean of Standard Deviations }\end{array}$ & 1.0110 & 1.0125 & 1.0137 & 1.0143 & 1.0132 \\
$\quad$ of HPR's & 0.0497 & 0.0617 & 0.0706 & 0.0815 & 0.1070 \\
Mean of Skews of HPR's & 0.3227 & 0.3854 & 0.5430 & 0.6877 & 1.2738 \\
Mean of Betas & 0.61 & 0.85 & 0.96 & 1.14 & 1.33 \\
\hline
\end{tabular}

N.B.: Stocks are grouped on the basis of the standard deviation of their HPR's, with the lowest standard deviation stocks in Group 1 and the highest standard deviation stocks in Group 5.

Table 1 contains some relevant data. The table was constructed in the following way: (1) The mean, standard deviation, skewness, and "beta" of the monthly holding period returns (the ratio of the month-end price plus any dividends to the preceding month-end price) were determined for each of 545 common stocks over the 252 months in the years 1945 through $1965 ;^{3}$ (2) the stocks were sorted into five groups of 109 securities per group according to the rank of their standard deviations of returns; and (3) the simple arithmetic averages of the three return distribution measures and the betas were struck across all of the stocks in each group. The 545 common stocks were randomly selected from among the 549 common stocks which were continuously listed on the New York Stock Exchange throughout the 1945-1965 period. ${ }^{4}$

The pattern of mean returns in the first row of Table 1 is consistent with prior findings. Proceeding from Group 1 (the lowest return variability stocks) through Group 4, the mean monthly yield rises at a decreasing rate from $1.10 \%$ to $1.43 \%$. However, for the group 5 (those stocks with the highest return variability), the mean monthly yield drops to $1.32 \%$. A possible explanation for this return decline is seen in the third row of the table. The average of the skews of the return distributions, which is positive for all groups, takes a large upward jump between Groups 4 and 5. If one is willing to accept the validity of "implicit forecasts" of stock return behavior-that on the average and over the long run investors realize ex post what they expect to realize ex ante-then these results are consistent with the hypothesis that the market is willing to trade off some expected returns from high risk common stocks in exchange for the enhanced opportunity they afford for extraordinarily large returns. ${ }^{5}$

but no satisfactory relationship was found between the mean and the skew of returns, possibly because of data weaknesses. Finally, two recent investigations of new issue performance in the United States [15] and Canada [13] have suggested that the low mean realized returns from these securities may be offset by the large positive skew in their return distributions.

3. The measure of skewness used here is the conventional measure of relative skewness equal to the third moment about the mean divided by the cube of the standard deviation. For a symmetric distribution this measure is equal to zero. The beta values were estimated by regressing each stock's monthly holding period returns on the link relatives of Fisher's Combination Investment. Performance Index over the entire twenty-one year period.

4. Holding period return data was taken from the Center for Research in Security Prices tapes.

5. The computations underlying Table 1 were replicated on the natural logarithms of the holding period returns (equivalent to continuously compounded rates of return) since logarithmic 
It is desirable to test the significance of the difference in the mean skews of Groups 4 and 5 because of the possibility that the observed increase may simply be due to the impact of a few extreme observations. The unbiased estimates of the variance of the underlying population skewness (that is, the variance of the individual stock skews around the mean group skew, adjusted for degrees of freedom) are 0.4341 for Group 4 and 2.0802 for Group 5. Because of the size differential in these two values, it cannot be assumed that the two groups of stocks come from populations with equal variances. In such a case, the $t$ statistic is approximately distributed as the $t$ distribution with a reduced number of degrees of freedom. ${ }^{6}$ For the data at hand the result is a value $t$ of 3.86 with 151 degrees of freedom, which is highly significant by usual standards. Therefore, it can be concluded that the stocks in Group 5 come from a population with a skew which is significantly more positive than the population underlying Group 4.

Stocks are sorted into risk classes in Table 1 according to the standard deviations of their returns in order to permit comparison with the Pratt study. However, in a market dominated by investors who can diversify their portfolios, what matters is only that portion of the return variability which cannot be diversified away - the so-called "nondiversifiable" or "systematic" risk of the securities in question - as established by the work of Sharpe [12] and Lintner [8]. It may be that the high return variability of the Group 5 stocks is largely diversifiable in nature; if so, the relatively low returns of these stocks may simply reflect their low portfolio-relevant risk rather than their skewed returns. Such risk is often quantified by reference to the covariance of a security's returns with those of a market index, or a transformation of this covariance, the "beta" coefficient. (The beta coefficient is simply the covariance divided by the

transformation is often suggested as means of normalizing security return distributions. The major impact of this transformation was to cause the mean returns to peak in the middle standard deviation group and decline thereafter. Other return behavior patterns, including the large jump in the skew between Groups 4 and 5, were basically unaltered.

6. For two samples of size $\mathrm{n}_{1}$ and $\mathrm{n}_{2}$ with means of $\bar{x}_{1}$ and $\bar{x}_{2}$ and estimated population variances of $\hat{\sigma}_{1}^{2}$ and $\hat{\sigma}_{2}^{2}$,

$$
\mathrm{t}=\frac{\overline{\mathrm{x}}_{1}-\overline{\mathrm{x}}_{2}}{\left(\frac{\hat{\sigma}_{1}^{2}}{\mathrm{n}_{1}}+\frac{\hat{\sigma}_{1}^{2}}{\mathrm{n}_{2}}\right)^{\frac{1}{2}}}
$$

with degrees of freedom equal to

$$
\frac{\left(\frac{\hat{\sigma}_{1}^{2}}{n_{1}}+\frac{\hat{\sigma}_{1}^{2}}{n_{2}}\right)^{2}}{\left(\frac{\hat{\sigma}_{1}^{2}}{n_{1}}\right)^{2} \frac{1}{n_{1}+1}+\left(\frac{\hat{\sigma}_{2}^{2}}{n_{2}}\right)^{2} \frac{1}{n_{2}+1}}
$$

This test requires that the underlying populations be normally distributed [16, pp. 522-524]. The central limit theorem and large sample size insure that the distributions are asymptotically normal in the present case. An alternative and accepted approach is simply to ignore comparatively large differences in the population variances when the samples are of equal size as they are here [4, p. 264]. The practical result of this alternative would be to increase the number of degrees of freedom over those offered in the text. 
variance of the market's returns; a constant across all securities.) The means of the betas for the stocks in each risk group in Table 1 rise continuously from Group 1 through Group 5, showing that the covariance or shared return variability of the Group 5 stocks with the typical stock (as represented by the market index) is higher than for the stocks in any other group. Therefore, the low average returns of the Group 5 stocks cannot be explained by their covariance or portfolio-relevant risk characteristics. ${ }^{7}$

\section{REFERENCES}

1. Fred Arditti. "Risk and the Required Return on Equity," Journal of Finance, Vol. 22 (March, 1967), pp. 19-36.

2. - "Another Look at Mutual Fund Performance," Journal of Financial and Quantitative Analysis, Vol. 6 (June, 1971), pp. 909-12.

3. Richard Brealey. An Introduction to Risk and Return from Common Stocks (Cambridge, Massachusetts: The M.I.T. Press, 1969).

4. Lincoln L. Chao. Statistics: Methods and Analysis (New York: McGraw-Hill, Inc., 1967).

5. J. R. Hicks. Value and Capital (London: Oxford University Press, 1939).

6. Jack Hirschleifer. "Risk, the Discount Rate, and Investment Decisions," American Economic Review, Vol. 51 (May, 1961), pp. 112-20.

7. A. Blaine Huntsman. "Natural Behavior Toward Risk and the Question of Value Determination," forthcoming in the Journal of Financial and Quantitative Analysis.

8. John Lintner. "Security Prices, Risk, and Maximal Gains from Diversification," Journal of Finance, Vol. 20 (December, 1965), pp. 587-615.

9. Shannon Pratt. "Relationship Between Risk and Return for Common Stocks," unpublished D.B.A. dissertation, Indiana University, 1966.

10. "Relationship Between Volatility of Past Returns and Levels of Future Returns for Common Stocks, 1926-1960," in E. Bruce Fredrikson (Editor), Frontiers of Investment Analysis, Revised Edition (Scranton, Pa.: International Textbook Company, 1971), pp. 33853.

11. Daniel Seligman. "Why the Stock Market Acts that Way," Fortune, Vol. 74 (November, 1966), pp. 154-57, 234, 238.

12. William F. Sharpe. "Capital Asset Prices: A Theory of Market Equilibrium Under Conditions of Risk," Journal of Finance, Vol. 19 (September, 1964), pp. 425-442.

13. David C. Shaw. "The Performance of Primary Common Stock Offerings: A Canadian Comparison," Journal of Finance, Vol. 26 (December, 1971), pp. 1101-1113.

14. Robert Soldofsky and Roger Miller. "Risk Premium Curves for Different Classes of LongTerm Securities, 1950-1966," Journal of Finance, Vol. 24 (June, 1969), pp. 429-45.

15. Hans R. Stoll and Anthony J. Curley. "Small Business and the New Issues Market for Equities," Journal of Financial and Quantitative Analysis, Vol. 5 (September, 1970), pp. 309-322.

16. Taro Yamane. Statistics, An Introductory Analysis, Second Edition (New York: Harper and Row, 1967).

7. As a further check, the stocks were re-sorted into risk classes according to the rank of their beta values with the following result.

Grand Means of HPR's

Mean of Standard Deviations of HPR's

Mean of Skews of HPR'S

Mean of Betas

\begin{tabular}{lllll}
\multicolumn{5}{c}{ Group } \\
\hline 1 & \multicolumn{1}{c}{2} & \multicolumn{1}{c}{3} & \multicolumn{1}{c}{4} & \multicolumn{1}{c}{5} \\
\hline 1.0109 & 1.0123 & 1.0137 & 1.0144 & 1.0135 \\
0.0524 & 0.0648 & 0.0721 & 0.0798 & 0.1014 \\
0.4491 & 0.4876 & 0.6929 & 0.6809 & 0.8989 \\
0.56 & 0.81 & 0.96 & 1.13 & 1.44
\end{tabular}

The pattern of mean returns and skews is substantially the same as in Table 1. Returns rise through Group 4 but decline for Group 5, while the mean skew is higher for Group 5 than Group 4. The unbiased estimates of the variance of the underlying population skewness are .3634 for Group 4 and 1.3707 for Group 5. Application of the tests outlined in Footnote 6 produced a t of 1.71 with 166 degrees of freedom, indicating that the difference in the skews is significant at the .05 level. The correspondence between results regardless of the risk measure employed is hardly surprising since the Spearman rank correlation coefficient between the two is 0.821 . 